\title{
TRABALHADORAS NO SETOR FORMAL DE TRANSPORTE BRASILEIRO: ANÁLISE PARA OS ANOS DE 1990, 2000 E 2010
}

WORKERS IN THE BRAZILIAN TRANSPORTATION SECTOR: ANALYSIS FOR THE

YEARS 1990, 2000 AND 2010

\author{
Cícera Viviane Barros ${ }^{1}$ \\ Silvana Nunes de Queiroz ${ }^{2}$
}

\begin{abstract}
RESUMO
Esse artigo tem como principal objetivo analisar a evolução da participação feminina no setor formal de transporte brasileiro, nos anos de 1990, 2000 e 2010. Para tanto, traça-se o perfil socioeconômico e demográfico dos ocupados em tal atividade. Ademais, fez-se uma revisão bibliográfica sobre a evolução da participação feminina no mercado de trabalho no mundo e no Brasil. A principal fonte de informação são os dados da Relação Anual de Informações Sociais (RAIS), do Ministério do Trabalho e do Emprego (MTE). A busca por realizar este estudo se dar por uma discussão relevante acerca dos problemas e avanços da mulher no mercado de trabalho. As mulheres já provaram que podem ser mais do que excelentes cozinheiras e donas de casa, se mostraram excelentes professoras, médicas, advogadas, economistas, engenheiras, bancárias, empresárias, entre outras profissões. Contudo, sofrem com a discriminação de gênero tanto em relação aos postos de trabalho quanto a diferenças de salários. É por esse motivo, que a inserção feminina no setor de transporte brasileiro deve ser analisada, dado que apesar do aumento da participação da mulher no setor, poucas pesquisas trataram de estudar esse lócus notadamente masculino.
\end{abstract}

Palavras-chave: Trabalhadoras; Setor de Transporte; Brasil.

\begin{abstract}
This article aims to analyze the evolution of female participation in the Brazilian transport sector in the years 1990, 2000 and 2010. Therefore, it draws up the socioeconomic and demographic profile of engaged in such activity. Moreover, at first, it took place bibliographical study on the evolution of female participation in the labor market in the world and in Brazil. The main source of information is the Annual Social Information (RAIS), the Ministry of Labor and Employment (MTE). The search for conduct this study be by a relevant discussion about the problems and progress of women in the labor market. Women have proven they can be more than excellent cooks and housewives, they showed excellent teachers, doctors, lawyers, economists, engineers, bank, entrepreneurs, among other professions. However, the woman suffers from gender discrimination both in relation to jobs as wage differentials. It is for this reason that integrating women in the Brazilian transportation sector should be analyzed,

\footnotetext{
${ }^{1}$ Graduanda em Economia na Universidade Regional do Cariri (URCA). E-mail: vivibarros93@hotmail.com

${ }^{2}$ Graduada em Economia pela Universidade Federal Rural do Rio de Janeiro (UFRRJ). Mestre em Economia pela Universidade Federal da Paraíba (UFPB). Doutora em Demografia pela Universidade Estadual de Campinas (Unicamp). Professora da Universidade Regional do Cariri (URCA). E-mail: silvanaqueirozce@yahoo.com.br
} 
given that despite the increased participation of women in the sector, few studies have tried to study this space / especially male locus.

Keywords: Workers; Transport sector; Brazil.

JEL: J7; J71

\section{Introdução}

Uma das mais importantes transformações sociais ocorridas no mundo e no Brasil foi o aumento da participação feminina no mercado de trabalho, a partir da década de 1970. Contudo, o mercado de trabalho brasileiro se caracteriza por diferenças salariais, o que o torna um importante elemento para a desigualdade entre os gêneros (ARROIO; RÉGNIER, 2002).

Apesar dos avanços, as mulheres continuam exercendo trabalhos domésticos e cumprindo suas responsabilidades com filhos e outras atividades relacionadas a família, representando uma sobrecarga para as mesmas, principalmente para as que realizam trabalhos econômicos (BRUSCHINI, 2007).

Mas segundo Probst (2003), o mundo está arriscando e acreditando em valores femininos, como o trabalho em equipe, indo contra o antigo individualismo, o estímulo ou a persuasão ao invés do autoritarismo e a cooperação no lugar da competição.

Contudo, a inserção da mulher no mercado de trabalho, ao longo dos anos, é caracterizada por um nível elevado de discriminação, não somente relacionada a capacidade e habilidade com que elas lidam com as ocupações, mas sobretudo no que tange à persistente desigualdade salarial entre os sexos (PROBST, 2003).

A discriminação além de inaceitável ${ }^{3}$, não condiz com os investimentos que a própria mulher tem realizado no aumento de sua competência e nem tão pouco com a dupla responsabilidade de chefe de família e de trabalhadora que desempenha na sociedade contemporânea (CARVALHO NETO, 2002).

Houve redução no número de filhos, e isso possibilita as mulheres trabalharem mais e dedicarem-se mais as suas atividades ou profissões. Sem dúvida, as oportunidades de trabalho aumentaram, isso porque, a escolaridade também aumentou e o ingresso nas universidades tornou-se mais acessível (BRUSCHINI, 1995).

\footnotetext{
${ }^{3}$ De acordo com o Art. 5 da Constituição Federal de 1988, todos são iguais perante a lei, sem distinção de qualquer natureza. I - homens e mulheres são iguais em direitos e obrigações, nos termos desta Constituição (Constituição Federal de 1988, p. 13).
} 
Contudo, segundo Bruschini e Lombarde (2003), apesar das mulheres ocuparem diversos cargos, e por mais que possuam bons empregos, a desigualdade salarial persiste. As mulheres trabalham em bancos, atuam no campo da medicina, em diversas áreas como a dermatologia, odontologia, pediatria, hemoterapia, entre outras. Trabalham também na engenharia civil, de minas e geologia e na agronômica. Elas ainda atuam também no setor de metalurgia e mecânica, exercem atividades "tidas" como masculinas, são executivas em grandes empresas e desempenham com muita competência suas funções (CHIES, 2010).

O que evidencia que mesmo com o preconceito e a discriminação, elas se inserem no mercado de trabalho e exercem as mesmas funções que os homens, e o mais interessante e prazeroso é que elas obtêm êxito em seus cargos (BRUSCHINI e BILA SORJ, 1994), apesar da diferença salarial.

Diante desse contexto, de inserção feminina em posto de trabalho em “nichos”/espaço ou 'lugar masculino', este estudo procura responder a seguinte questão: como tem evoluído a participação das trabalhadoras no setor formal de transporte brasileiro? Quem são as trabalhadoras e trabalhadores ocupados no setor formal de transporte brasileiro?

Esta pesquisa justifica-se por ampliar o conhecimento a respeito do processo de inserção feminina no mercado de trabalho, especificamente o ingresso da mulher no setor formal de transporte nacional, espaço/lócus notadamente masculino. Deve-se ressaltar que poucos trabalhos acadêmicos abordaram essa temática.

Para o alcance dos objetivos propostos, serão adotados os métodos descritivo e explicativo, para uma melhor análise e compreensão da pesquisa. $\mathrm{O}$ método descritivo irá descrever de maneira detalhada o tema proposto, enquanto o segundo método (explicativo) irá identificar a teorização que envolve o tema, expondo e analisando os principais conceitos relacionados, complementado, assim, a análise que conduza a obtenção dos resultados, servindo como base de sustentação dos conhecimentos expostos. Ademais, a principal fonte de informação são os dados da Relação Anual de Informações Sociais (RAIS), do Ministério do Trabalho e do Emprego (MTE).

A primeira seção é composta por essa introdução. A segunda faz uma breve contextualização sobre a inserção da mulher no mercado de trabalho no mundo e no Brasil. A terceira apresenta os procedimentos metodológicos. A quarta analisa a inserção ocupacional feminina no setor formal de transporte brasileiro vis-à-vis a 
masculina, e traça o perfil socioeconômico e demográfico de ambos os sexos. A quinta trata da conclusão do estudo.

\section{INSERÇÃO FEMININA NO MERCADO DE TRABALHO NO MUNDO E NO BRASIL: BREVE CONTEXTUALIZAÇÃO}

Desde o século XVI com destaque para os séculos XIX e XX, as mulheres buscavam direitos democráticos iguais ao homem relacionados ao voto, divórcio, educação e trabalho, caracterizado como movimento feminista (CUNHA, 2013).

A inserção da mulher no mercado de trabalho mundial se deu por volta do século XX no período da Primeira e Segunda Guerra Mundial, dado que os homens saíram para as guerras e muitas vezes não voltavam ou quando voltavam, estavam impossibilitados de trabalhar. Assim, as mulheres tinham que assumir as responsabilidades familiares, passando a ocuparem alguns dos postos de trabalhos tidos como masculinos (PROBST, 2003).

Na Europa, entre os séculos XVI e XVIII, mulheres também ocupavam o comércio, especialmente no ramo têxtil. Na França, em específico, ainda na fase conhecida como antigo regime (Sistema político e social francês, estabelecido a partir do final da Idade Média, caracterizado pela divisão de Estados em clero, nobreza e população francesa, estando incluídos os camponeses e burgueses), as mulheres já participavam do comércio, mas ainda eram vistas pela sociedade em geral como inferiores aos homens, a partir de uma relação de submissão, obediência, incapacidade civil e até dependência. A mulher via no casamento estabilidade, elevação de sua situação econômica, e isso lhe propiciava uma espécie de um bem ou alegria pessoal. (GUIRALDELLI, 2007).

Mas no século XIX, no contexto da Primeira Revolução Industrial, o quadro de mulheres empregadas aumentou consideravelmente, dando início a um período extenso de trabalho nas fábricas. As mulheres tinham jornada de trabalho mais elevada e possuíam salários muitos mais baixos em relação aos homens. A partir daí, o movimento feminista se tornou mais forte, em busca de melhorias trabalhistas e em defesa das operárias (CUNHA, 2013).

Para Nadal (2010), desde o final do século XIX, as organizações femininas originárias de movimentos operários faziam protestos em países da Europa e também nos Estados Unidos. As longas jornadas de trabalho calculadas em aproximadamente quinze horas diárias e os salários vergonhosos e insignificantes, introduzidos pela 
Revolução Industrial, acarretaram em várias greves. As mesmas reivindicavam condições mais propícias para trabalhar, e o fim do trabalho infantil, que era comum nas grandes e pequenas fábricas.

Com relação às histórias que remetem à criação do Dia Internacional da Mulher, acredita-se que a data teria surgido a partir do incêndio em uma fábrica têxtil em Nova York, em 25 de março de 1911, causando a morte de cerca de cento e trinta operárias, deixando os seus corpos totalmente carbonizados. Alimenta-se no curso da história que as mesmas buscavam melhores condições de trabalho e licença maternidade remunerada, e que o incêndio foi para mostrar quem possuía poder. Mas não restam dúvidas que esse incidente marcou expressivamente a trajetória das lutas feministas ao longo do século $\mathrm{XX}$, mas se sabe que os acontecimentos que levaram a criação desta data já se "manifestavam" desde o século XVI (NADAL, 2010).

No tocante ao Brasil, foi a partir do século XVIII que se começou a falar em reivindicação dos direitos da mulher e a palavra feminismo apareceu apenas no final do século XIX, com a chegada do Iluminismo e os seus ideais de liberdade e igualdade, além da Revolução Francesa (CUNHA, 2013).

No início do século XX, no Brasil, as movimentações em busca dos diretos femininos se intensificaram, em meio aos grupos anarquistas, que mais uma vez buscavam apenas condições mais favoráveis para se viver (NADAL, 2010).

A partir do final da década de 1960, no movimento feminista, ganha bandeira a busca da liberação sexual, impulsionado pelo aumento dos contraceptivos no Brasil, o que fez com que iniciasse uma onda de movimentos liderados pelas mulheres brasileiras. Na década seguinte, em 1970, marca a luta pela igualdade no trabalho (CUNHA, 2013).

Nesse contexto, Pereira, Santos e Borges (2005) relatam que, desde os anos 1960, a porcentagem de mulheres ativas no mercado de trabalho e no meio social e econômico aumentou significativamente no Brasil. Sem dúvida, isso se deve, entre diversos fatores, aos movimentos sociais e políticos ocorridos nas décadas de 1960 e 1970 de caráter mundial. As mulheres foram impulsionadas a estudarem mais e assim, passaram a se inserir no mercado de trabalho de uma forma ainda mais sólida.

Um fator de grande importância para o crescente e contínuo envolvimento das mulheres no mercado de trabalho decorre da alta da inflação, da estagnação econômica e as mudanças realizadas no Brasil na década de 1980 concentradas na estrutura do emprego. Deve-se ressaltar que para evitar o empobrecimento das famílias foi reforçada 
a participação das mulheres no mercado de trabalho. Isso sem esquecer-se das excessivas transformações sociais que ao longo dos anos perduravam (LEONE, 1997).

Nos anos 1990, com as diversas transformações sociais (movimentos feministas) e econômicas (abertura da economia, reestruturação produtiva e tentativas de estabilização econômica) houve uma drástica redução do número de empregos, concentrada especificamente no setor organizado da economia e na moderna indústria de transformação (BORGES; GUIMARÃES, 1997). Essa redução se deu dentre outros fatores, quando no governo Collor de Mello (1990 a 1992) aumentou-se o nível de importações, e como consequência, algumas indústrias faliram (VIECELI, 2011).

Nos anos 2000, mesmo com a diminuição da pobreza e das desigualdades sociais que vieram para somar e resultar em um bom crescimento do mercado interno, através do aumento dos rendimentos das famílias menos favorecidas, as diferenças entre a geração de empregos para o sexo feminino comparado ao masculino ainda são significativas. Isso mostra que o elevado crescimento de ofertas formais em diversos postos de trabalho brasileiros, são insuficientes para suprir a demanda decorrente do intenso crescimento da População Economicamente Ativa (PEA) feminina (VIECELI, 2011).

Apesar dos avanços, atualmente, as mulheres permanecem discriminadas e desconhecem sua tamanha importância para o bem-estar socioeconômico. Elas não exercem no âmbito doméstico o papel de mãe ou esposa associada ao termo dona-decasa, mas ao trabalho doméstico sem remuneração, feito e visto como "obrigação" pela sociedade. E isto faz do sexo feminino "alvo" de discriminação por meio de distinção entre gênero, religião e raça (MELO, 2002). Ainda falta um detalhamento, uma melhor compreensão dos "papéis" de ambos os sexos no âmbito doméstico. Com certeza, sem este compreendimento, a dificuldade é ainda maior e assim, a mulher continuará sendo vista como a única responsável por todos os afazeres domésticos (SOARES; SABÓIA, 2007).

Vale lembrar que o número de mulheres brasileiras tidas como chefes ou referência da família vem aumentando com o passar dos anos. Segundo o IBGE, em 1996, 20,81\% das famílias eram chefiadas por mulheres, e esse número aumentou em 2000 para 26,55\%. É um avanço que deve ser considerado. A PNAD (Pesquisa Nacional por Amostra de Domicílio) de 2011, mostra que 37,4\% das famílias brasileiras tinham como referência a mulher. Um dos fatores que contribuíram para isto, é que a mulher está buscando maior independência financeira, e sua renda deixou de ser 
complementar e passou a ser uma contribuição essencial. Decorrente disto, elas se definem como provedoras do lar (CYMBALUK, 2012).

Mesmo com os números apresentados acima, é importante destacar que por questões culturais, que buscam manter de certa forma os valores patriarcais, as famílias ainda atribui a figura de chefe ao homem (BORGES, 2006).

A participação das mulheres no mercado de trabalho não é algo que deve ser considerado como causa de uma comemoração intensa, pois para estarem onde estão as mesmas viram no trabalho uma solução para o fim da dependência financeira que tinham em seus maridos, onde a renda familiar baseava-se na renda dos homens e também foi uma forma das empresas pagarem remunerações menores e como isto era viável, as mesmas se deixaram fluir (ROSSINI, 1988).

Através de todas as mudanças ocorridas, as mulheres passaram a participar cada vez mais da economia brasileira, e em alguns casos ocupam cargos de prestígio, tais como: engenharia, advocacia, medicina, e muitas são juízas. Sendo que estas profissões antes eram ocupadas somente por homens. Assim, o que se observa é que elas estão presentes nos cargos de chefia, no âmbito social, cultural e também da saúde (CARVALHO, 2012).

Elas estão ocupando seu espaço perante a sociedade brasileira, impondo todas as suas necessidades, mostrando que são essenciais para a economia e para o desenvolvimento social, mesmo com a desigualdade de gênero ainda existente (CARVALHO, 2012).

\section{PROCEDIMENTOS METODOLÓGICOS}

\subsection{Fonte de dados}

A principal fonte de informações são os dados da Relação Anual de Informações Sociais (RAIS), do Ministério do Trabalho e Emprego (MTE). A RAIS é uma das principais fontes de informação no tocante ao mercado de trabalho formal brasileiro, que através de um censo anual, visa suprir as necessidades de controle, de estatísticas e de informações às entidades governamentais da área social. Possui como principais características: abrangência geográfica de todo o território nacional; natureza de levantamento de registro administrativo; periodicidade anual e com uma cobertura de cerca de $97 \%$ do mercado formal de trabalho brasileiro (RAIS, 2010). 
A RAIS sem dúvida é um importante instrumento de gestão governamental do setor do trabalho. Instituída pelo Decreto n 76.900 , de 23/12/75. Os seus objetivos são:

- o suprimento às necessidades de controle da atividade trabalhista no País;

- o provimento de dados para a elaboração de estatísticas do trabalho;

- a disponibilização de informações do mercado de trabalho às entidades governamentais (Disponível em: 〈http://www.rais.gov.br/sitio/index.js>, 2015 p. 2).

Os dados coletados ainda constituem significativos insumos para o atendimento do Ministério da Fazenda, do Interior e da Previdência Social através da (Disponível em: 〈http://www.rais.gov.br/sitio/index.js>, 2015 p. 2):

- legislação da nacionalização do trabalho;

- de controle dos registros do FGTS;

- dos sistemas de arrecadação e de concessão e benefícios previdenciários;

- de estudos técnicos de natureza estatística e atuarial;

- de identificação do trabalhador com direito ao abono salarial PIS/PASEP.

A RAIS é um registro administrativo obrigatoriamente preenchido e encaminhado ao MTE por todo estabelecimento (formalmente constituído) em território brasileiro. A declaração é feita somente pela internet, por empregadores privados ou de administração pública direta ou indireta. E aqueles estabelecimentos que não possuem empregados ou não estiverem com suas atividades ativas no ano-base são obrigados a declarar a RAIS negativa. Cabe destacar que a não declaração ou emissão de declaração falsa ou inexata, está sujeita ao pagamento de multa por bimestre de atraso, contados até a data de entrega da RAIS respectiva. Os valores de tal multa podem variar (KINCZESKI, 2011).

Quanto ao recorte temporal do estudo, os anos são 1990, 2000 e 2010. No tocante ao recorte geográfico, o motivo da escolha foi devido a pouca existência de estudos que mostrem a evolução da mulher no mercado de formal trabalho no setor de transporte brasileiro.

\subsection{Conceitos}

Os conceitos adotados neste estudo seguem as definições que constam na documentação da RAIS (2010, p. 32-37).

i) Tipo de Trabalhadores

- Trabalhadores formais: qualquer ocupação trabalhista, manual ou intelectual, com benefícios e carteira profissional assinada. Consiste em trabalho fornecido por uma empresa, com todos os direitos trabalhistas garantidos. O papel ocupado ou a função 
que a pessoa desempenha em alguma atividade econômica lhe confere uma remuneração. No caso dos empregados de uma empresa, por exemplo, essa remuneração pode ser chamada de salário ou de vencimentos, sendo esta muito utilizada para se referir aos rendimentos dos que trabalham em órgãos do governo.

- O trabalhador celetista: é aquele cuja relação de emprego é regida pela CLT (Consolidação das Leis do Trabalho), independentemente de o empregador ser do setor público ou privado;

- Trabalhadores avulsos: são conforme definidos em lei: estivadores, alvarengueiros, conferentes de carga ou descarga, vigias portuários, amarradores, trabalhadores avulsos do serviço de bloco, trabalhadores avulsos de capatazia, arrumadores, ensacadores de café, cacau, sal e similares e trabalhadores na indústria de extração do sal, na condição de avulsos, que prestam serviços por meio de sindicatos;

- Trabalhadores temporários: regidos pela Lei $n^{\circ}$ 6.019, aqueles que prestam trabalho a uma empresa para atender à necessidade transitória de substituição de seu pessoal regular e permanente, ou ao acréscimo extraordinário de serviço;

- Trabalhadores por prazo determinado: regidos pela Lei $n^{\circ}$ 9.601, são aqueles que podem ser contratados por um período máximo de dois anos, desde que esse tipo de contrato tenha sido previsto em convenção ou em acordo coletivo.

\subsection{Variáveis}

Com base na literatura sobre o tema (Bruschini e Bila Sorj, 1994; Bruschini, 1995; Arroio e Régnier, 2002; Carvalho Neto, 2002; Melo, 2002; Bruschini e Lombarde, 2003; Probst, 2003; Pereira, Santos e Borges, 2005; Soares e Sabóia, 2007; Nadal, 2010), os referidos autores apontam o sexo, a idade e a escolaridade como os principais determinantes para o "gap" salarial entre mulheres e homens no mercado de trabalho. Sendo assim, as variáveis selecionadas para o alcance dos objetivos propostos foram:

Sexo: Masculino/ Feminino.

Faixa Etária: De 10 a 14 anos, de 15 a 17 anos, de 18 a 24 anos, de 25 a 29 anos, de 30 a 39 anos, de 40 a 49 anos, de 50 a 64 anos e 65 ou mais anos de idade.

Escolaridade: Analfabeto; Até $5^{\mathrm{a}}$ ano Incompleto, $5^{\mathrm{a}}$ ano Completo Fundamental, $6^{\text {a }}$ ao $9^{\text {a }}$ ano do Fundamental, Fundamental Completo, Ensino Médio Incompleto, Ensino Médio Completo, Superior Incompleto e Superior Completo.

Tempo de Serviço: Menos de 1 ano, 1 a menos de 3 anos, 3 a menos de 5 anos e 5 ou mais anos.

Tamanho do Estabelecimento: Micro (1 a 19 trabalhadores), Pequena (20 a 99 trabalhadores), Média (100 a 499 trabalhadores) e Grande (acima de 499 trabalhadores).

Remuneração dos Trabalhadores: Até 1,00 salário mínimo, de 1,01 a 2,00 salários mínimos, de 2,01 a 3,00 salários mínimos, de 3,01 a 5,00 salários mínimos, de 5,01 a 10,00 salários mínimos, de 10,01 a 20,00 salários mínimos e Mais de 20,00 salários mínimos. 
Remuneração dos Trabalhadores e Escolaridade: Analfabeto, Ensino Fundamental Incompleto até o Fundamental Completo, Ensino Médio Incompleto até o Médio Completo e Ensino Superior Incompleto até o Superior Completo. Todos ganhando de Até 1,00 salário mínimo a mais de 20,00 salários.

Após a extração das variáveis acima, através do acesso on-line a base de dados da RAIS/MTE, as mesmas foram transferidas para a planilha de cálculo do Excel, onde criou-se tabelas e gráficos que serão analisados neste capítulo.

\section{Trabalhadoras no Setor Formal de Transporte Brasileiro}

\section{1 - Sexo}

Em relação às ocupações no setor formal de transporte brasileiro, em 1990, 1.035.950 de trabalhadores estavam inseridos em tal atividade. Em 2000, esse número aumenta levemente para 1.390.777, com variação de 34,25\% (Tabela 1), superando a variação em todas as atividades produtivas do país ${ }^{4}$ (13,06\%), entre 1990/2000. Dez anos depois (2010), dado o quadro de melhora na economia brasileira, o número de trabalhadores no setor de transporte dar um salto significativo para 2.308 .822 de pessoas, com variação de $66,01 \%$ contra $68,01 \%$ nas demais atividades do país.

Tabela 1 - Participação absoluta de trabalhadores no setor formal de transporte brasileiro, segundo o sexo - 1990/2000/2010

\begin{tabular}{l|c|c|c|cc}
\hline \multirow{2}{*}{ Sexo } & $\mathbf{1 9 9 0}$ & $\mathbf{2 0 0 0}$ & $\mathbf{2 0 1 0}$ & \multicolumn{2}{c}{ Variação (\%) } \\
\cline { 2 - 6 } & Abs. & Abs. & Abs. & $\mathbf{1 9 9 0 / 2 0 0 0}$ & $\mathbf{2 0 0 0 / 2 0 1 0}$ \\
\hline Masculino & 914.635 & 1.180 .654 & 1.886 .418 & 29,08 & 59,78 \\
Feminino & 121.315 & 210.123 & 422.404 & 73,20 & 101,03 \\
\hline Total & $\mathbf{1 . 0 3 5 . 9 5 0}$ & $\mathbf{1 . 3 9 0 . 7 7 7}$ & $\mathbf{2 . 3 0 8 . 8 2 2}$ & $\mathbf{3 4 , 2 5}$ & $\mathbf{6 6 , 0 1}$ \\
\hline
\end{tabular}

Fonte: Elaborada pelas autoras a partir da RAIS/MTE (vários anos).

Quanto ao ingresso feminino, em uma atividade considerada nicho do sexo masculino, em 1990, 88,29\% (914.635) dos trabalhadores eram homens e somente $11,71 \%$ (121.315) mulheres. Em 2000, observa-se pequena queda na participação relativa masculina $(84,89 \%$ ou 1.180 .654$)$, enquanto elas aumentam $(15,11 \%$ ou 422.404), resultando em uma variação de $29,08 \%$ para os homens e 73,20\% para as mulheres. Em 2010, o percentual masculino continuou caindo, agora representando

\footnotetext{
${ }^{4}$ Esses dados foram calculados pelas autoras, mas encontram-se omitidos no estudo.
} 
$81,70 \%$ (1.886.418) e o feminino 18,30\% (422.404), implicando em uma variação de $59,78 \%$ para eles e $101,03 \%$ para elas, evidenciando que elas mais que duplicaram sua inserção no setor de transporte brasileiro.

\section{Gráfico 1 - Participação relativa de trabalhadores no setor formal de transporte brasileiro, segundo o sexo - 1990/2000/2010 (\%)}

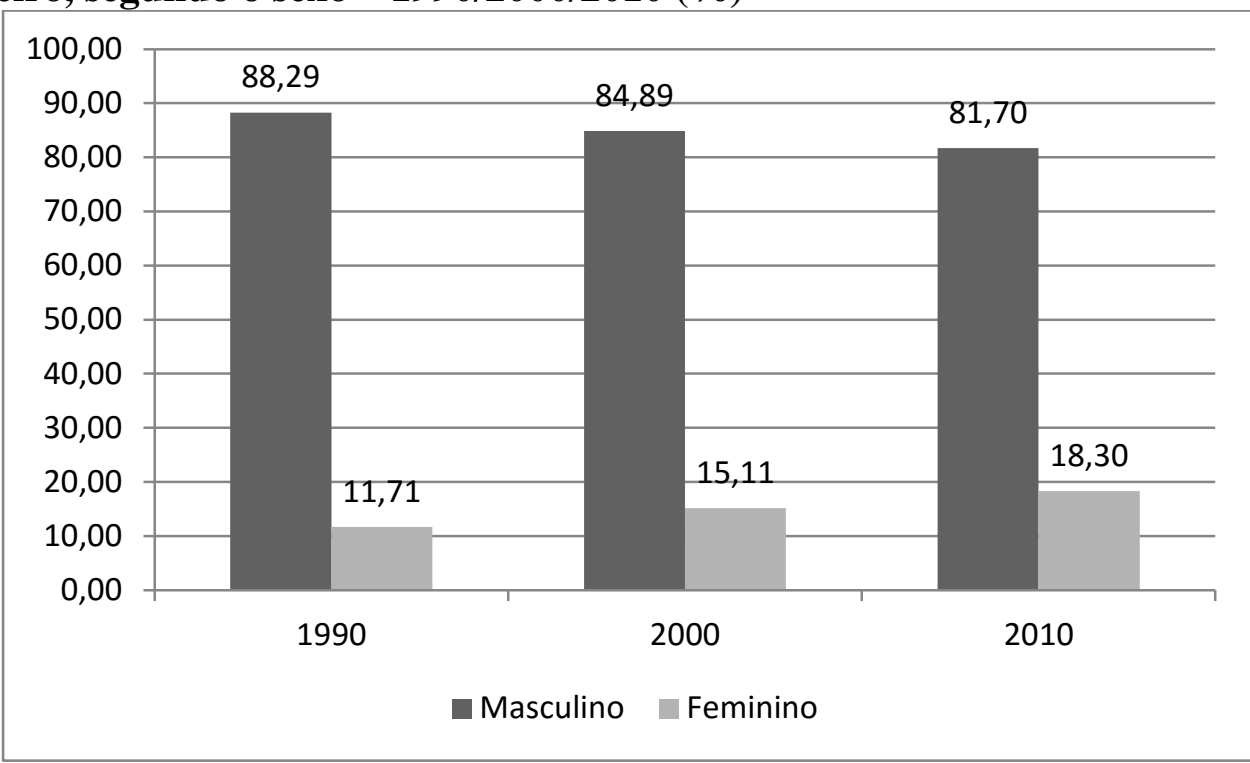

Fonte: Elaborado pelas autoras a partir da RAIS/MTE (vários anos).

A inserção da mulher nesse setor se dar antes de tudo, pelo fato das mesmas sentirem a necessidade de autonomia financeira e demonstrarem para o 'mundo' e si mesmas que são capazes de realizar trabalhos fora do domicílio e em atividades tidas como masculina, quando lhes é dado poder/liberdade/autonomia (empoderamento). Elas são responsáveis, encaram "inteiramente" e de frente qualquer cargo que lhes é dado, dominando, aprendendo e exercendo profissões que antes eram impossíveis de serem ocupadas por mulheres, buscando superar-se e surpreender, não importando o setor que vão atuar ou cargo que vão ocupar.

\section{2 - Faixa Etária}

No tocante a idade, observa-se que nos anos analisados, a maioria dos trabalhadores inseridos formalmente no setor de transporte brasileiro, tanto homens quanto mulheres, estão situados na faixa etária de 30 a 39 anos, dado que nesta idade o trabalhador está em plena idade ativa, dispõe de maior saúde e vigor físico, portanto, tem mais disposição para trabalhar e o mercado tem maior demanda por sua mão de obra. 
Tabela 2 - Trabalhadores no setor formal de transporte brasileiro por faixa etária $-1990 / 2000 / 2010(\%)$

\begin{tabular}{l|cccc|ccc}
\hline \multirow{2}{*}{ Faixa Etária } & \multicolumn{3}{|c|}{ Homem } & \multicolumn{3}{c}{ Mulher } \\
\cline { 2 - 7 } & $\mathbf{1 9 9 0}$ & $\mathbf{2 0 0 0}$ & $\mathbf{2 0 1 0}$ & $\mathbf{1 9 9 0}$ & $\mathbf{2 0 0 0}$ & $\mathbf{2 0 1 0}$ \\
\hline 10 A 14 & 0,13 & 0,00 & 0,01 & 0,06 & 0,00 & 0,02 \\
15 A 17 & 1,38 & 0,35 & 0,47 & 1,61 & 0,51 & 1,25 \\
18 A 24 & 16,1 & 13,22 & 11,78 & 18,43 & 21,68 & 18,27 \\
25 A 29 & 17,43 & 15,84 & 14,67 & 18,13 & 19,51 & 19,81 \\
30 A 39 & 34,91 & 33,86 & 31,90 & 37,96 & 31,58 & 33,33 \\
40 A 49 & 20,49 & 26,33 & 23,05 & 17,90 & 21,12 & 17,85 \\
50 A 64 & 9,04 & 9,86 & 17,12 & 5,78 & 5,40 & 9,12 \\
65 OU MAIS & 0,52 & 0,53 & 1,00 & 0,14 & 0,20 & 0,35 \\
\hline Total & $\mathbf{1 0 0 , 0 0}$ & $\mathbf{1 0 0 , 0 0}$ & $\mathbf{1 0 0 , 0 0}$ & $\mathbf{1 0 0 , 0 0}$ & $\mathbf{1 0 0 , 0 0}$ & $\mathbf{1 0 0 , 0 0}$ \\
\hline
\end{tabular}

Fonte: Elaborada pelas autoras a partir da RAIS/MTE (vários anos).

Quanto a faixa etária de 10 a 14 anos, composta por crianças e adolescente, em 1990, a sua participação era quase insignificante para o sexo masculino $(0,13 \%)$ e o feminino (0,06\%). Em 2000, foi zero para ambos os sexos. Dez anos depois (2010) foi de $0,01 \%$ para eles e $0,02 \%$ para elas. Esse resultado é positivo para o "controle" da exploração do trabalho infantil e mostra maior ingresso das crianças na escola, exercendo os seus direitos previstos em Lei ${ }^{5}$.

Com relação a faixa etária de 50 a 64 anos, em1990, a sua participação foi de $9,04 \%$ para o sexo masculino e 5,78\% para o feminino. Enquanto em 2000, esse número aumenta para eles $(9,86 \%)$ e reduz para elas $(5,40 \%)$. Em 2010, salta para $17,12 \%$ para o homem e aumenta para 9,12\% para a mulher. Nota-se, portanto, um aumento substancial na participação para ambos os sexos, em especial para os homens, destacando a importância da demanda no setor de transporte por trabalhadores experientes.

Outra faixa etária que merece destaque é a de 65 ou mais, onde a experiência faz a diferença. Assim, em 1990, os homens representavam 0,52\% e as mulheres 0,14\% dos trabalhadores formalizados no setor de transporte. Já em 2000, eles eram 0,53\% e elas 0,20\%. Enquanto em 2010, 1,00\% representava o sexo masculino e 0,35\% o feminino. O que se observa é que cresce a participação de idosos e idosas no setor de transporte brasileiro, evidenciando que mesmo com a idade avançada e com direitos reservados

\footnotetext{
${ }^{5}$ Certamente a criação da Lei №. 8.609, de 13 de julho de 1990, que dispõe sobre o Estatuto da Criança e do Adolescente que, de acordo com Art. 60 da Constituição Federal de 1988, proibi qualquer trabalho a menores de quatorze anos de idade, salvo na condição de aprendiz. Assim, jovens com menos de 18 anos podem ingressar no setor de transporte, porém como aprendizes e/ou estagiários (mas sempre com a supervisão de um adulto, de preferência com experiência nesse setor), podendo permanecer por até dois anos assegurados com todos os diretos previstos em Lei.
} 
(aposentados), esses trabalhadores tem experiência para oferecer, ensinar e por que não "colher" bons resultados.

\section{3 - Escolaridade}

Com relação ao nível de escolaridade, em 1990, a maioria dos homens empregados no setor de transporte formal no Brasil tinha o $5^{\text {a }}$ ano Completo do Ensino Fundamental $(32,72 \%)$, enquanto as mulheres eram maioria $(29,18 \%)$ em uma faixa educacional mais elevada (Médio Completo). Em 2000, os homens melhoram o seu nível de instrução e passam a ser maioria no Ensino Fundamental Completo $(21,87 \%)$, enquanto as mulheres permanecem no Médio Completo, porém aumentam a sua participação relativa (41,79\%). Ao longo dos anos 2000, a educação no país avança e os homens passam a ser grande parte no Ensino Médio Completo (50,44\%) se aproximando das mulheres $(53,48 \%)$.

Tabela 3 - Trabalhadores no setor formal de transporte brasileiro por escolaridade $-1990 / 2000 / 2010(\%)$

\begin{tabular}{l|ccc|c|cc|c}
\hline \multirow{2}{*}{ Escolaridade } & \multicolumn{3}{c|}{ Homem } & \multicolumn{3}{c}{ Mulher } \\
\cline { 2 - 7 } & $\mathbf{1 9 9 0}$ & $\mathbf{2 0 0 0}$ & $\mathbf{2 0 1 0}$ & $\mathbf{1 9 9 0}$ & $\mathbf{2 0 0 0}$ & $\mathbf{2 0 1 0}$ \\
\hline Analfabeto & 2,38 & 1,00 & 0,11 & 6,11 & 0,66 & 0,07 \\
Até 5a Incompleto & 10,45 & 4,85 & 2,20 & 6,3 & 1,96 & 0,94 \\
$5^{\text {a }}$ Completo Fund. & 32,72 & 16,36 & 4,09 & 14,43 & 6,23 & 1,61 \\
6 a 9 Fundamental & 20,97 & 20,69 & 8,89 & 9,8 & 7,14 & 3,37 \\
Fundamental Compl. & 14,34 & 21,87 & 15,67 & 12,02 & 11,30 & 6,53 \\
Médio Incompleto & 5,27 & 8,41 & 8,92 & 9,09 & 7,35 & 6,04 \\
Médio Completo & 9,68 & 20,10 & 50,44 & 29,18 & 41,79 & 53,48 \\
Superior Incompleto & 1,42 & 2,26 & 2,49 & 5,1 & 9,02 & 7,34 \\
Superior Completo & 2,77 & 4,46 & 7,19 & 7,98 & 14,55 & 20,62 \\
\hline Total & $\mathbf{1 0 0 , 0 0}$ & $\mathbf{1 0 0 , 0 0}$ & $\mathbf{1 0 0 , 0 0}$ & $\mathbf{1 0 0 , 0 0}$ & $\mathbf{1 0 0 , 0 0}$ & $\mathbf{1 0 0 , 0 0}$ \\
\hline
\end{tabular}

Fonte: Elaborada pelas autoras a partir da RAIS/MTE (vários anos).

Quanto ao nível Superior Completo, é evidente o aumento substancial das mulheres ao longo dos anos analisados. Em 1990, foi de 2,77\% para eles e 7,98\% para elas. Já em 2000, esse percentual quase duplica para ambos os sexos: 4,46\% (eles) e 14,55\% (elas). Dez anos depois (2010), foi de 7,19\% (homens) e 20,62\% (mulheres). Esse resultado mostra que as mulheres ocupadas no setor de transporte brasileiro são mais instruídas em relação aos homens.

Estamos na era da globalização, do conhecimento e da informação, e o mercado de trabalho faz as suas exigências. Quer-se criatividade com qualidade e responsabilidade para acompanhar a tecnologia a qual se estar vivenciando. Isso sem 
dúvida gera grandes mudanças no mercado de trabalho, deixando-o mais seletivo, e mais restrito aos profissionais aptos as transformações e exigências as quais as empresas passam diariamente (TREVISAN, 2001).

\section{4 - Remuneração dos Trabalhadores}

Sob a ótica da remuneração (Tabela 4), verifica-se que em 1990, a maioria dos trabalhadores formais recebia de 5,01 a 10,00 salários mínimos, sendo 31,65\% homens e $28,61 \%$ mulheres. Contudo, em 2000, houve piora no rendimento, a maioria dos homens passou a se concentrar na faixa de 3,01 a 5,00 salários $(34,49 \%)$ e as mulheres de 2,01 a 3,00 salários (23,99\%). Já em 2010, intensifica-se a precarização, dado que ambos os sexos passaram a ser maioria na faixa de 1,01 a 2,00 salários mínimos, com os homens figurando com $31,65 \%$ e as mulheres em pior situação $(45,13 \%)$.

Tabela 4 - Trabalhadores no setor formal de transporte brasileiro segundo rendimento em salário mínimo - 1990/2000/2010 (\%)

\begin{tabular}{l|c|c|c|c|c|c}
\hline \multicolumn{1}{c|}{$\begin{array}{c}\text { Faixa de } \\
\text { Remuneração } \\
\text { Média (SM) }\end{array}$} & $\mathbf{1 9 9 0}$ & $\mathbf{2 0 0 0}$ & $\mathbf{2 0 1 0}$ & $\mathbf{1 9 9 0}$ & $\mathbf{2 0 0 0}$ & $\mathbf{2 0 1 0}$ \\
\cline { 2 - 7 } & 0,89 & 0,99 & 1,83 & 1,8 & 1,73 & 4,57 \\
\hline Até 1,00 & 8,62 & 9,65 & 31,65 & 16,58 & 16,64 & 45,13 \\
1,01 a 2,00 & 16,83 & 20,77 & 29,27 & 16,68 & 23,99 & 20,41 \\
2,01 a 3,00 & 27,25 & 34,49 & 23,93 & 18,25 & 23,59 & 13,87 \\
3,01 a 5,00 & 31,65 & 24,45 & 8,96 & 28,61 & 19,85 & 10,69 \\
5,01 a 10,00 & 10,58 & 6,03 & 3,01 & 14,55 & 10,08 & 4,22 \\
10,01 a 20,00 & 4,18 & 3,62 & 1,34 & 3,53 & 4,12 & 1,10 \\
Mais de 20,00 & $\mathbf{1 0 0 , 0 0}$ & $\mathbf{1 0 0 , 0 0}$ & $\mathbf{1 0 0 , 0 0}$ & $\mathbf{1 0 0 , 0 0}$ & $\mathbf{1 0 0 , 0 0}$ & $\mathbf{1 0 0 , 0 0}$ \\
\hline Total & &
\end{tabular}

Fonte: Elaborada pelas autoras a partir da RAIS/MTE (vários anos).

Uma das remunerações analisadas que merece destaque é a de 10,01 a 20,00 salários mínimos, que com o passar dos anos, apresenta considerável redução, chegando a ser quase irrelevante. Em 1990, tinha uma participação de 10,58\% para os homens e de 14,55\% para as mulheres. Em 2000, reduziu para 6,03\% (eles) e 10,08\% (elas). Já em 2010 , os percentuais continuaram a decrescer: $3,01 \%$ para eles e $4,22 \%$ para elas. $\mathrm{O}$ que se evidencia é que as mulheres são maioria em todos os anos analisadas.

Por fim, a remuneração de mais de 20,00 salários mínimos não possui percentuais significativos, porém, ocorrem oscilações nos anos analisados, referentes a ambos os sexos. Em 1990, os homens eram maioria com 4,18\% e as mulheres logo atrás com 3,53\%. Em 2000, os homens declinam para 3,62\% e as mulheres passam a ser 
maioria com 4,12\%. Dez anos depois (2010), os homens arrefecem para 1,34\%, enquanto as mulheres vêm logo atrás com 1,10\%.

Barros e Mendonça (1995) apontam como determinantes das desigualdades de renda no mercado de trabalho brasileiro, a discriminação (étnicas e gênero), alguns tipos de segmentação (ramo de atividade e formalidade ocupacional), e aspectos ligados ao capital humano (experiência e escolaridade do trabalhador). Sendo assim, a próxima subseção analisa se ao possuir o mesmo grau de escolaridade, ainda há diferença no rendimento entre mulheres e homens empregados no setor de transporte brasileiro.

\section{5 - Remuneração dos Trabalhadores e Escolaridade}

De acordo com a Tabela 5, que apresenta os trabalhadores analfabetos empregados no setor de transporte brasileiro, constata-se aumento expressivo de homens e mulheres ganhando de 1,01 a 2,00 salários mínimos. Em 1990, os homens representavam $12,77 \%$ e as mulheres $10,22 \%$. Em 2000, observa-se leve aumento para eles $(15,69 \%)$ e mais que o dobro para elas $(27,01 \%)$. Dez anos depois, o percentual para ambos salta bruscamente: 70,10\% (eles) e 65,68\% (elas).

Tabela 5 - Trabalhadores no setor formal de transporte brasileiro segundo rendimento em salário mínimo e escolaridade (Analfabeto) - 1990/2000/2010 (\%)

\begin{tabular}{l|ccccccc}
\hline \multirow{2}{*}{$\begin{array}{c}\text { Faixa de } \\
\text { Rendimento em SM }\end{array}$} & \multicolumn{5}{c}{ Analfabeto } \\
\cline { 2 - 7 } & $\mathbf{1 9 9 0}$ & $\mathbf{2 0 0 0}$ & $\mathbf{2 0 1 0}$ & $\mathbf{1 9 9 0}$ & $\mathbf{2 0 0 0}$ & $\mathbf{2 0 1 0}$ \\
\hline Até 1,00 & 2,06 & 2,98 & 9,69 & 1,15 & 13,40 & 8,01 \\
1,01 a 2,00 & 12,77 & 15,69 & 70,10 & 10,22 & 27,01 & 65,68 \\
2,01 a 3,00 & 12,18 & 21,03 & 14,19 & 5,21 & 22,89 & 2,97 \\
3,01 a 5,00 & 18,51 & 28,30 & 4,69 & 6,30 & 15,06 & 23,34 \\
5,01 a 10,00 & 27,41 & 19,85 & 1,01 & 54,44 & 6,24 & 0,00 \\
10,01 a 20,00 & 16,01 & 5,53 & 0,09 & 18,82 & 9,42 & 0,00 \\
Mais de 20,00 & 11,05 & 6,60 & 0,23 & 3,85 & 5,97 & 0,00 \\
\hline Total & $\mathbf{1 0 0 , 0 0}$ & $\mathbf{1 0 0 , 0 0}$ & $\mathbf{1 0 0 , 0 0}$ & $\mathbf{1 0 0 , 0 0}$ & $\mathbf{1 0 0 , 0 0}$ & $\mathbf{1 0 0 , 0 0}$ \\
\hline
\end{tabular}

Fonte: Elaborada pelas autoras a partir da RAIS/MTE (vários anos).

O que está explícito é a intensa precarização no mercado de trabalho brasileiro. E, dado o baixo nível de instrução dos trabalhadores (analfabetos), a tendência foi a concentração tanto de homens quanto de mulheres nas faixas iniciais de rendimento.

A partir disso, em 1990, os homens eram 2,06\% e as mulheres $1,15 \%$ ganhando até 1 salário mínimo. Em 2000, o percentual masculino aumenta levemente para 2,98\% 
e o feminino significativamente para $13,40 \%$. Já em 2010, os homens aumentam consideravelmente para 9,69\% e elas sofrem declínio para $8,01 \%$.

Para Chahad (1999), o baixo ou nenhum nível de escolaridade é um fator determinante para o estado atual do mercado de trabalho brasileiro. Influencia na baixa produtividade, rotatividade de mão de obra, geração de emprego e desemprego, e remuneração.

Outro destaque são os trabalhadores remunerados com até 20,00 salários mínimos. Em 1990, os homens representavam 11,05\% e as mulheres 3,85\%. Já em 2000 , eles arrefecem para $6,60 \%$ e elas aumentam para $5,97 \%$. Com o passar dos anos (2010), os homens diminuíram significativamente sua participação $(0,23 \%)$, e as mulheres não ficaram atrás, com $0 \%$ delas ganhando mais de vinte salários.

Mais uma vez fica evidente a importância do estudo e o grau de exigência do mercado. Em 1990 e 2000 foi possível ganhar mais de 20 salários mínimos no setor de transporte, sendo analfabeto. Contudo, dado às exigências do mercado de trabalho, as novas formas de organização da produção e do trabalho, em 2010, praticamente não há homens ou mulheres, com esse nível de escolaridade, ganhando altos rendimentos.

Rifkin (1996) coloca que para os analfabetos adultos ou com pouca instrução, tornasse difícil serem instruídos para um cargo e/ou setor da elite. Portanto, o resultado é o desemprego, ou um cargo "baixo" em um setor não tão requisitado e com baixa remuneração.

A Tabela 6 traz informações dos ocupados no Ensino Fundamental Incompleto até o Fundamental Completo e mostra que em 1990, na faixa de rendimento de 2,01 a 3,00 salários, os homens eram 18,80\% e as mulheres representam pouco mais de 24,06\%. Em 2000, eles aumentam levemente para $21,84 \%$ e elas saltam para $34,71 \%$. Em 2010, eles crescem substancialmente para $33,98 \%$ e elas reduzem significativamente para 3,03\%. Contudo, conforme a Tabela 6, esse resultado mostra que as mulheres, entre 2000 e 2010, "migraram" para uma faixa de rendimento mais elevada (de 3,01 a 5,00 salários).

Tabela 6 - Trabalhadores no setor formal de transporte brasileiro segundo rendimento em salário mínimo e escolaridade (Ensino Fundamental Incompleto até o Fundamental Completo) - 1990/2000/2010 (\%)

\begin{tabular}{l|c|c|c|c|c|c}
\hline \multirow{2}{*}{$\begin{array}{c}\text { Faixa de } \\
\text { Rendimento em SM }\end{array}$} & \multicolumn{6}{|c}{ Ensino Fundamental Incompleto até Fundamental Completo } \\
\cline { 2 - 7 } & $\mathbf{1 9 9 0}$ & $\mathbf{2 0 0 0}$ & $\mathbf{2 0 1 0}$ & $\mathbf{1 9 9 0}$ & $\mathbf{2 0 0 0}$ & $\mathbf{2 0 1 0}$ \\
\hline Até 1,00 & 0,94 & 1,14 & 1,84 & 3,08 & 3,51 & 2,82
\end{tabular}




\begin{tabular}{lcccccc}
1,01 a 2,00 & 9,46 & 10,84 & 39,11 & 27,75 & 30,28 & 24,76 \\
2,01 a 3,00 & 18,80 & 21,84 & 33,98 & 24,06 & 34,71 & 3,03 \\
3,01 a 5,00 & 30,31 & 38,57 & 21,95 & 21,46 & 23,35 & 69,17 \\
5,01 a 10,00 & 32,65 & 25,37 & 2,86 & 17,35 & 6,28 & 0,20 \\
10,01 a 20,00 & 7,05 & 1,94 & 0,24 & 5,49 & 1,42 & 0,02 \\
Mais de 20,00 & 0,79 & 0,30 & 0,03 & 0,81 & 0,46 & 0,00 \\
\hline Total & $\mathbf{1 0 0 , 0 0}$ & $\mathbf{1 0 0 , 0 0}$ & $\mathbf{1 0 0 , 0 0}$ & $\mathbf{1 0 0 , 0 0}$ & $\mathbf{1 0 0 , 0 0}$ & $\mathbf{1 0 0 , 0 0}$ \\
\hline
\end{tabular}

Fonte: Elaborada pelas autoras a partir da RAIS/MTE (vários anos).

Outra faixa que merece destaque é a de 3,01 a 5,00, onde os percentuais são bastante consideráveis. Em 1990, os homens representavam 30,31\% e as mulheres 21,46\%. Em 2000, observa-se aumento para ambos os sexos: 38,57\% (eles) e 23,35\% (elas). Já em 2010, eles sofrem redução (21,95\%) e elas aumentam bruscamente $(69,17 \%)$.

Nas três últimas faixas (de 5,01 a mais de 20 salários), observa-se redução de ambos os sexos. Em 1990, as três faixas representam 40,49\% para os homens e quase a metade para as mulheres $(23,65 \%)$. Em 2000, eles eram 27,61\% e elas 8,16\%. Dez anos depois, eles representavam $3,13 \%$ e elas somente $0,22 \%$. Isso revela que além de reduzir tanto a participação masculina quanto a feminina, mesmo com as mulheres tendo o mesmo nível de instrução em relação aos homens, as mesmas recebem remuneração inferior. Assim, Bruschini e Lombarde (2003) relatam que as mulheres podem ocupar os melhores cargos (que na teoria possuem os melhores salários), porém, a desigualdade salarial persiste.

Em relação a Tabela 7, que expõe as faixas de salários referentes ao Ensino Médio Incompleto até o Completo, observa-se que, em 1990, os homens (31,63\%) e as mulheres $(35,84 \%)$ são maioria na faixa de 5,01 a 10,00 salários mínimos. Entretanto, nos anos 2000, com a intensificação da precarização dos postos de trabalho no Brasil, eles $(31,18 \%)$ e elas $(26,34 \%)$ passaram a se concentrar em uma faixa de remuneração mais baixa (de 3,01 a 5,00 salários). Isso mostra a migração de ambos os sexos para faixas de rendimentos inferiores. Ao longo dos anos 2000, tal tendência permanece. Contudo, em 2010, os homens migraram para a faixa de 1,01 a 2,00 salários (40,48\%), enquanto elas permaneceram $(44,50 \%)$ na faixa de 3,01 a 5,00 salários.

Tabela 7 - Trabalhadores no setor formal de transporte brasileiro segundo rendimento em salário mínimo e escolaridade (Ensino Médio Incompleto até o Médio Completo) - 1990/2000/2010 (\%)

\begin{tabular}{c|c|c} 
Faixa de & Ensino Médio Incompleto até o Médio Completo \\
\cline { 2 - 3 } Rendimento em SM & Homem & Mulher \\
\hline
\end{tabular}




\begin{tabular}{lcccccccc}
\hline & $\mathbf{1 9 9 0}$ & $\mathbf{2 0 0 0}$ & $\mathbf{2 0 1 0}$ & $\mathbf{1 9 9 0}$ & $\mathbf{2 0 0 0}$ & $\mathbf{2 0 1 0}$ \\
\hline Até 1,00 & 0,51 & 0,76 & 2,34 & 0,93 & 1,38 & 4,33 \\
1,01 a 2,00 & 5,35 & 8,60 & 40,48 & 9,93 & 15,38 & 38,22 \\
2,01 a 3,00 & 11,27 & 22,07 & 31,33 & 14,19 & 25,47 & 10,64 \\
3,01 a 5,00 & 18,46 & 31,18 & 18,44 & 18,88 & 26,34 & 44,50 \\
5,01 a 10,00 & 31,63 & 23,57 & 6,17 & 35,84 & 21,90 & 2,07 \\
10,01 a 20,00 & 23,54 & 10,16 & 1,05 & 17,89 & 7,90 & 0,22 \\
Mais de 20,00 & 9,24 & 3,66 & 0,18 & 2,34 & 1,63 & 0,02 \\
\hline Total & $\mathbf{1 0 0 , 0 0}$ & $\mathbf{1 0 0 , 0 0}$ & $\mathbf{1 0 0 , 0 0}$ & $\mathbf{1 0 0 , 0 0}$ & $\mathbf{1 0 0 , 0 0}$ & $\mathbf{1 0 0 , 0 0}$ \\
\hline
\end{tabular}

Fonte: Elaborada pelas autoras a partir da RAIS/MTE (vários anos).

Nesse caso, isso sugere melhor remuneração das mulheres com Ensino Fundamental Incompleto até o Fundamental Completo. Leone e Baltar (2006) destacam que os homens com ensino médio vêm passando por uma queda acentuada no rendimento, cedendo, portanto, maior espaço para as mulheres.

Outra faixa de rendimento que merece destaque é até 1,00 salário mínimo, ao apresentar aumento ao longo dos anos. Em 1990, os homens figuravam com 0,51\% e as mulheres com 0,93\%. Em 2000, eles representavam 0,76\% e elas 1,38\%. Já em, 2010, os homens figuram com $2,34 \%$ ao passo que as mulheres aumentam para $4,33 \%$, sendo quase o dobro da participação deles. Isso mostra que embora os percentuais sejam pequenos, cresce ao longo do tempo, com destaque para as mulheres, apontando para a intensificação da precarização dos postos de trabalho no setor de transporte brasileiro.

No tocante as três últimas faixas de rendimento (de 5,01 até mais de 20 salários), observa-se redução substancial. Em 1990, os homens eram 64,41\% e as mulheres $56,07 \%$. No ano de 2000, eles representavam $37,39 \%$ e elas $31,43 \%$. Dez anos depois (2010), eles representam 7,4\% e elas somente 2,31\%. Esse resultado denota intensa e rápida precarização no rendimento do trabalhador do setor de transporte brasileiro, com destaque para as mulheres, que mesmo possuindo a mesma escolaridade em relação aos homens, apresentam menor participação nas faixas salariais mais elevadas e, por outro lado, maior concentração na menor faixa salarial (até 1 salário).

Por sua vez, a Tabela 8 traz a participação dos trabalhadores no setor de transporte brasileiro com Ensino Superior Incompleto até o Superior Completo e os seus rendimentos. Inicialmente, constata-se que em 1990, os homens eram maioria $(46,24 \%)$ na faixa de mais de 20,00 salários, enquanto as mulheres eram $(32,14 \%)$ na faixa de 10,01 a 20,00 salários. Em 2000, eles se mantêm na mesma faixa (10,01 a 20,00), mas diminuem a sua participação para $34,53 \%$, enquanto elas migram para uma faixa inferior: de 5,01 a 10 salários, com participação de 31,23\%. No ano de 2010, eles são 
maioria (25,35\%) em uma faixa inferior (de 5,01 a 10 salários) a que se mantinham, e as mulheres, mais uma vez, migram para uma remuneração mais baixa (de 3,01 a 5,00 salários), com participação de 26,67\%.

Tabela 8 - Trabalhadores no setor formal de transporte brasileiro segundo rendimento em salário mínimo e escolaridade (Ensino Superior Incompleto até o Superior Completo) - 1990/2000/2010 (\%)

\begin{tabular}{l|c|c|c|c|c|c}
\hline \multirow{2}{*}{$\begin{array}{c}\text { Faixa de } \\
\text { Rendimento em SM }\end{array}$} & \multicolumn{3}{c}{ Ensino Superior Incompleto até Superior Completo } \\
\cline { 2 - 7 } & $\mathbf{1 9 9 0}$ & $\mathbf{2 0 0 0}$ & $\mathbf{2 0 1 0}$ & $\mathbf{1 9 9 0}$ & $\mathbf{2 0 0 0}$ & $\mathbf{2 0 1 0}$ \\
\hline Até 1,00 & 0,16 & 0,23 & 0,56 & 0,38 & 0,37 & 1,01 \\
1,01 a 2,00 & 1,33 & 1,88 & 12,70 & 2,93 & 3,55 & 20,08 \\
2,01 a 3,00 & 2,15 & 5,02 & 16,92 & 5,31 & 8,79 & 20,61 \\
3,01 a 5,00 & 5,55 & 10,80 & 20,07 & 11,55 & 18,33 & 26,67 \\
5,01 a 10,00 & 16,32 & 20,19 & 25,35 & 32,09 & 31,23 & 21,65 \\
10,01 a 20,00 & 28,25 & 27,35 & 16,78 & 32,14 & 24,38 & 8,21 \\
Mais de 20,00 & 46,24 & 34,53 & 7,63 & 15,60 & 13,36 & 1,77 \\
\hline Total & $\mathbf{1 0 0 , 0 0}$ & $\mathbf{1 0 0 , 0 0}$ & $\mathbf{1 0 0 , 0 0}$ & $\mathbf{1 0 0 , 0 0}$ & $\mathbf{1 0 0 , 0 0}$ & $\mathbf{1 0 0 , 0 0}$ \\
\hline
\end{tabular}

Fonte: Elaborada pelas autoras a partir da RAIS/MTE (vários anos).

A partir dessa dinâmica, observa-se que ao longo dos vinte anos em estudo (1990 a 2010), tanto a participação masculina e notadamente a feminina se deslocam para faixa de remuneração mais baixa, apesar de apresentarem um patamar mais elevado de educação. Ademais, apesar possuir o mesmo nível de instrução dos homens, as mulheres recebem remuneração inferior a eles, retratando a discriminação contra elas no setor de transporte brasileiro, ratificando à tendência nas demais atividades do país.

Quanto às duas primeiras faixas de rendimento (até 2,00 salários mínimos), constata-se crescente participação de ambos os sexos. Em 1990, eles representavam $1,49 \%$ e elas 3,31\%. Em 2000, os homens aumentaram a sua participação para 2,11\% e as mulheres para 3,92\%. Dez anos depois (2010), verifica-se um salto para ambos os sexos, com destaque o feminino que aumentou para $21,09 \%$ e eles para $13,26 \%$.

Quanto às duas últimas faixas (de 10,01 a mais de 20 salários), observa-se redução para os dois sexos. Em 1990, os homens representavam 74,49\% e as mulheres 47,74\%. Em 2000, eles eram 61,88\% e elas 37,74\%. Em 2010, eles declinam para $24,41 \%$ e elas representam somente $9,98 \%$. Isso mostra a diminuição na participação feminina e masculina, mais escolarizada, nas faixas salariais de maior rendimento, em que a mulher é mais prejudicada, dado que mesmo possuindo o mesmo nível de educação, elas são minoria em relação a mão de obra masculina. 


\section{Conclusões}

6. Referências Bibliográficas O objetivo desse artigo foi analisar a evolução da participação feminina no setor formal de transporte brasileiro, nos anos de 1990, $2000 \mathrm{e}$ 2010. Para tanto, traçou-se o perfil socioeconômico e demográfico dos ocupados em tal atividade. Ademais, a princípio, realizou-se revisão bibliográfica sobre a evolução da participação feminina no mercado de trabalho no mundo e no Brasil.

Os primeiros resultados revelam, ao longo dos anos em estudo, aumento absoluto e, notadamente, relativo, na participação feminina no setor formal de transporte brasileiro, entretanto, os homens permanecem maioria expressiva $(81,70 \%)$ em tal segmento.

No tocante ao perfil dos empregados no ramo dos transportes, tanto homens quanto mulheres são maioria na faixa etária de 30 a 39 anos. Com relação à escolaridade, as mulheres são mais instruídas em relação ao sexo oposto. Em 2010, elas têm maior participação relativa no ensino superior completo quando comparado a eles e menor participação nas menores faixas de escolaridade. Contudo, ainda assim, as mulheres são maioria relativa nas faixas salariais mais baixas e minoria nas mais elevadas.

$\mathrm{Na}$ busca de resultados mais robustos, sobre a discriminação de gênero no mercado de trabalho, ao analisar a relação entre sexo, escolaridade e remuneração, observou-se que a mulher, mesmo apresentando o mesmo nível de instrução em relação aos homens, ela auferem menores rendimentos, mostrando que permanece a discriminação salarial e de gênero.

Portanto, o que se constatou foi a intensa precarização nas ocupações no setor formal de transporte brasileiro para ambos os sexos. Ademais, embora as mulheres tenham aumentado o seu ingresso em tal atividade, e mesmo que busquem se qualificar, enfrentam uma competitividade desleal, que favorece ao sexo masculino, ocasionada pela desvalorização de sua mão de obra, por meio de níveis salariais mais baixos, mesmo possuindo o mesmo nível de escolaridade em relação a eles.

Enfim, estudos posteriores poderão aprofundar mais motivos para a diferença relevante na presença de homens e mulheres no setor formal de transporte brasileiro, apesar do aumento na participação feminina, bem como as diferenças salariais. 


\section{Referências}

ARROIO, A.; RÉGNIER, E. P. Mercado de trabalho: oportunidades e desafios para o presente. Disponível em: $\langle$ http://www.senac.br/BTS/272/boltec272d.htm>Acesso em 17 outubro 2014.

BARROS, R. P.; MENDONÇA, Roseane. Os Determinantes da Desigualdade do Brasil. Rio de Janeiro: IPEA, 1995. (Texto para discussão nº. 377).

BORGES, A. Desemprego e precarização em Regiões Metropolitanas: um olhar a partir das famílias. Análise sobre a Pesquisa Nacional por Amostra de Domicílios (PNAD 2004). (Edição Especial). Bahia, Parcerias estratégicas - n. 22, 2006.

BORGES, A.; GUIMARÃES, I. B. A mulher e mercado de trabalho nos anos 90: o caso da região metropolitana de Salvador. Bahia, 1997.

Brasil. [Constituição (1988)]. Constituição da República Federativa do Brasil: texto constitucional promulgado em 5 de outubro de 1988, com as alterações adotadas pelas Emendas Constitucionais nos 1/1992 a 68/2011, pelo Decreto Legislativo $n^{\circ}$ 186/2008 e pelas Emendas Constitucionais de Revisão nos 1 a 6/1994. - 35. ed. Brasília : Câmara dos Deputados, Edições Câmara, 2012. 454 p. - (Série textos básicos ; n. 67).

BRUSCHINI, C. Desigualdades de gênero e deslocamentos da força de trabalho. São Paulo, 1995.

; LOMBARDI, R. M. (2003). Mulheres e homens no mercado de trabalho brasileiro: um retrato da década de 1990. In: As novas fronteiras das desigualdades: homens e mulheres no mercado de trabalho. Margaret Maruani \& Helena Hirata (Orgs). São Paulo: Editora SENAC.

; SORJ, B. Novos Olhares: Mulheres e Relações de Gênero no Brasil. São Paulo: Editora Marco Zero, 1994.

Trabalho e gênero no Brasil nos últimos dez anos. Caderno de

Pesquisa, v. 37, n. 132, set./dez. 2007.

CARVALHO, M. C. S. Considerações sobre as mulheres no mercado de trabalho e desenvolvimento. Roraima, 2012.

CARVAlhO NETO, J. F. Mulher e Trabalho: Continuidade ou Ruptura? Conjuntura \& Planejamento, Salvador: SEI, n.92, p.3032, 2002.

CHAHAD, J. P. Z. Estabilização e desemprego em tempo de mudança: realidade e desafios no caso brasileiro. In: II Encontro Regional da Associação Brasileira de Estudos do Trabalho. João Pessoa: ABET, 1999, v.2, p.497531.

CHIES, P. V. Identidade de gênero e identidade profissional no campo de trabalho. São Paulo (2010). 
CYMBALUK, F. Mulheres chefes de família não são mais pobres e nem sozinhas, diz pesquisadora. São Paulo(2012).

CUNHA, C. Direitos femininos: uma luta por igualdade e direitos civis. Disponível em:

<http://vestibular.uol.com.br/resumodasdisciplinas/atualidades/direitosfemininosumalut aporigualdadeedireitoscivis.htm> Acesso em 14 de nov. de 2014.

GUIRALDELli, R. Presença feminina no Mundo do Trabalho: História e Atualidade. São Paulo, 2007.

LEONE, E. T.; BALTAR, P. Diferenças de rendimento do trabalho de homens e mulheres com educação superior nas metrópoles. São Paulo, v. 23, n. 2, p. 355367, jul./dez. 2006.

Mulher, mercado de trabalho e pobreza: um estudo dainserção da mulher na atividade econômica e suas implicações para a família. Campinas: IEUNICAMP, 1997. (Relatório de Pesquisa).

MELO, H. P. A invisibilidade do trabalho feminino nas estatísticas. Rio de Janeiro, 2002.

NADAL, P. Por que 8 de março é o Dia Internacional da Mulher? Revista gente que educa. São Paulo, 2010.

PEREIRA, R S.; SANTOS, D. A.; BORGES, W. A mulher no mercado de trabalho. Maranhão,2005.

PROBST, E. R. A Evolução da mulher no mercado de trabalho. Disponível em: 〈http://www.posuniasselvi.com.br/artigos/rev0205.pdf>Acesso em: 28 mar. 2015.

RIFKIN, J. “O fim dos empregos”. Makron Books, São Paulo, 1996.

ROSSINI, R. E. Geografia e Gênero: a mulher na lavoura canavieira paulista. Tese de Livre Docência. São Paulo: USP, 1988.

SOARES, C; e SABÓIA, A. L. Tempo, trabalho e afazeres domésticos: um estudo com base nos dados da Pesquisa Nacional por Amostra de Domicílios de 2001 e 2005. Rio de Janeiro, 2007.

VIECELI, C. P. Mulher e trabalho no Brasil: características, avanços e permanências (1960-2009). Porto Alegre, 2011.

Submetido em: 16/02/16

Aceito em: 01/06/2016 